\title{
Rabbit nictitating membrane conditioning: Lower limit of the effective interstimulus interval
}

\author{
W. RONALD SALAFIA, RICHARD W. LAMBERT, KAREN C. HOST, \\ NICOLAS L. CHIAIA, and JULIO J. RAMIREZ \\ Fairfield University, Fairfield, Connecticut 06430
}

\begin{abstract}
In three experiments, the nictitating membrane response of rabbits was conditioned for 10 daily sessions at interstimulus intervals (ISIs) ranging from 48 to $125 \mathrm{msec}$, followed by a shift to $250 \mathrm{msec}$ for 5 days. At tested ISIs shorter than $67 \mathrm{msec}$, there was no evidence of conditioning, and postshift performance revealed neither facilitation nor interference as a result of the first 10 conditioning sessions. Postshift performance of groups conditioned at preshift ISIs of $67 \mathrm{msec}$ or longer revealed a gradient of increasing savings with increasing ISI. One of the groups in Experiment 1, initially conditioned at $250 \mathrm{msec}$ ISI and then shifted to $48 \mathrm{msec}$, exhibited extinction of the previously well-conditioned response. Analysis of CR-onset latencies substantiated the absence of associative effects at very short ISIs. It was concluded that there is a temporal limit below which classical conditioning of the nictitating membrane response of rabbits employing forward CS-US pairing does not occur.
\end{abstract}

The detailed interstimulus interval (ISI) function for the rabbit nictitating response (NMR), established by Smith, Coleman and Gormezano (1969), indicates that the minimum ISI required for conditioning is between 50 and $100 \mathrm{msec}$. Smith et al. found no evidence of conditioning at ISIs of $-50,0$ or $50 \mathrm{msec}$, but increasingly rapid acquisition at ISIs of $100 \mathrm{msec}$ and higher. Recent studies, however, have seemed to show substantial conditioning at 50 -msec ISI (Patterson, 1970) as well as simultaneous and backward conditioning in rats and rabbits (e.g., Ayres, Mahoney, Proulx, \& Benedict, 1976; Barker, Suarez, \& Gray, 1974; Heth \& Rescorla, 1973; Keith-Lucas \& Guttman, 1975; Mahoney \& Ayers, 1976; Plotkin \& Oakley, 1975; Siegel \& Domjan, 1974; Wagner \& Terry, 1975), a situation which appears to challenge whether, indeed, there is a value of ISI below which there is no conditioning. Additionally, in two studies from this laboratory (Salafia, Daston, Bartosiak, Hurley, \& Martino, 1974; Salafia, Martino, Cloutman, \& Romano, 1979), substantial variation in acquisition rate was demonstrated as a function of US locus. Specifically, circumorbital placement of US electrodes yielded more rapid acquisiton of the NMR than either postorbital or ear-tip shock, even though all placements reliably elicited URs. Smith et al. had employed a postorbital electrode placement for US presentation, which was approximately the same as that employed by Salafia et al. (1979). Thus, several lines

Portions of Experiments 1 and 2 formed the substance of a paper read at the annual meeting of the Psychonomic Society, St. Louis, November 1976. We are grateful to Stephen J. Zaccaro and Barbara Bunk Wilhelmy for their assistance in the running of Experiment 2. of evidence suggest that either there is no limiting value of ISI or, if there is, it may be lower than heretofore suspected. The present study employed ISI shifts as a potentially more sensitive indicator of associative strength, in an attempt to evaluate NMR conditioning at short ISIs and to clarify the question of the limiting value of ISI.

\section{EXPERIMENT 1}

Initially, it was decided to run two groups at ISIs of either 50 or $250 \mathrm{msec}$ and, after several sessions, to reverse the ISIs. The expectation was that even if there were no direct evidence of conditioning at the short ISI, any subtle effects would be displayed in the postshift performance at the more optimal value.

At this stage of the investigation, as well as for Experiment 2, apparatus for precise calibration of the timers was not available, so we had to relay on the timer dial settings. After calibrating equipment was acquired, the $50-\mathrm{msec}$ dial setting on the ISI timer was found to be $48 \mathrm{msec}$, although with excellent repeat reliability of less than $\pm .05 \mathrm{msec}$. The 250 -msec setting was accurate with the same degree of repeat reliability.

\footnotetext{
Method

Subjects. The subjects were eight experimentally naive New Zealand rabbits, 70 to 90 days old at the start of the experiment. They were maintained on ad-lib food and water and housed in light- and climate-controlled quarters. Four rabbits were randomly assigned to each of two groups, designated in terms of the preand postshift ISI as Group 48-250 and Group 250-48. One rabbit in Group 250-48 died prior to the start of experimentation, leaving three subjects in that group.
} 
Apparatus. The subjects were run concurrently in a room containing four separate sound-attenuating cubicles serviced independently by control and recording equipment located in an adjacent room. A panel in front of each subject contained two impedancematched speakers used to present the auditory CS and a continuous $65-\mathrm{dB}$ (re: $20 \mu \mathrm{N} / \mathrm{m}^{2}$ ) white noise for masking during the intertrial interval (ITI). A panel behind each subject contained two houselights and connectors for the transducers and shock. A four-channel shock source delivered the US to two stainless steel wound clips attached circumorbitally, with one placed below the inferior eyelid and the other posterior to the temporal canthus.

Immediately prior to each experimental session, the animals were placed in Plexiglas restraining boxes. Movements of the NM were monitored by a small photoelectric transducer mounted on the subject's head and mechanically coupled to a suture in the NM of the right eye. Signals from the transducer were amplified and graphically recorded by a Beckman R411 polygraph at a chart speed of $250 \mathrm{~mm} / \mathrm{sec}$. A CR was defined as a pen deflection of at least $.5 \mathrm{~mm}$ relative to a UR of at least $20 \mathrm{~mm}$ and occuring within the ISI on paired trials and within 1 sec after CS offset on test trials. At the maximum amplification levels used, we calculated that these criteria permitted accurate monitoring of membrane extensions of approximately $.2 \mathrm{~mm}$. The CS was a $1,000-\mathrm{Hz}$ 85 -dB (re: $20 \mu \mathrm{N} / \mathrm{m}^{2}$ ) tone presented for either 98 or $300 \mathrm{msec}$, and the US was a $2-\mathrm{mA}, 60-\mathrm{Hz}$ shock overlapping the last $50 \mathrm{msec}$ of the CS. The ITI was a constant $30 \mathrm{sec}$.

Procedure. On the day before the first experimental session each subject was prepared by having a surgical silk suture implanted into the NM of the right eye under local anesthetic $.5 \%$ proparacaine hydrochloride). Stainless steel wound-clip electrodes were attached to the skin approximately $4 \mathrm{~mm}$ below the inferior eyelid and $4 \mathrm{~mm}$ posterior to the temporal canthus of the right eye. Each subject was then placed in an experimental cubicle for a 15-min adaptation period.

Conditioning sessions began on the day following adaptation and continued one per day for 15 days. Each daily session consisted of 20 trials with 18 CS-US pairings and 2 CS-alone test trials (Trials 7 and 14). Group 48-250 was run for 10 days at an ISI of $48 \mathrm{msec}$ and then shifted to $250 \mathrm{msec}$ for the next 5 days. Group 250-48 was run initially at $250 \mathrm{msec}$ and after 10 days shifted to $48 \mathrm{msec}$.

\section{Results and Discussion}

CR frequency, all trials. Acquisition curves for all 20 daily trials for the two groups are presented in

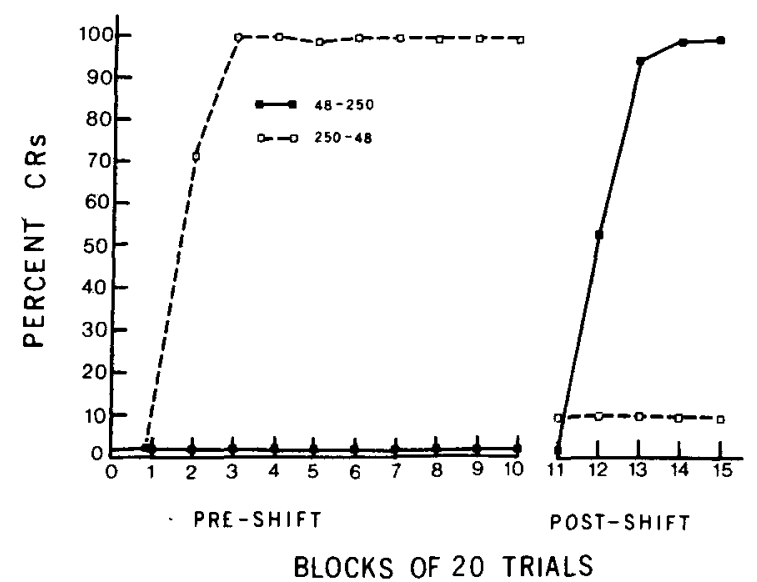

Figure 1. Mean percent CRs during 10 days of acquisition at 48- or 250-msec ISI, followed by reversal of ISI for the last 5 days.
Figure 1. Group 48-250 showed no evidence of conditioning over the first 10 blocks of trials, while Group 250-48 conditioned rapidly and stably, reaching $100 \%$ CRs by the third block. Since all frequencies for Group 48-250 were zero with no variation, further statistical analysis of these data was deemed superfluous.

After the shift, Group 48-250 conditioned readily, reaching $100 \%$ CRs by Day 13 . Interestingly, the postshift acquisition curve for this group was virtually identical to the preshift curve of Group 250-48. A 2 by 5 mixed factorial ANOVA on the CR frequency data for Group 250-48, Days 1-5 vs. Group 48-250, Days 11-15 revealed only a significant trial blocks effect $[F(4,20)=43.29, p<.001]$. There was no significant difference in the performance of the two groups $(F<1)$, nor was there a Groups by Trial Blocks interaction $(F<1)$. Thus, there was no evidence of either facilitation or interference with acquisition over the first 10 days of conditioning at the short ISI. The postshift performance for Group 250-48 shows a precipitous drop to the $10 \%$ level. This drop could be misleading, however, as is evident in the testtrial analysis.

CR frequency, test trials. Figure 2, which presents acquisition curves for test trials only, shows the same pattern of preshift performance as depicted in Figure 1. The postshift data, however, show Group 250-48 continuing to perform at the $100 \%$ level. This means that all of the postshift CRs depicted in Figure 1 for this group occurred on test trials and were evident only because of the extended scoring criterion on test trials. This is substantiated by mean postshift CR-onset latency of $112 \mathrm{msec}$ for the group. Thus, although the animals almost certainly continued to generate CRs on the CS-US paired trials, such responses would have been obscured by URs due to the short ISI.

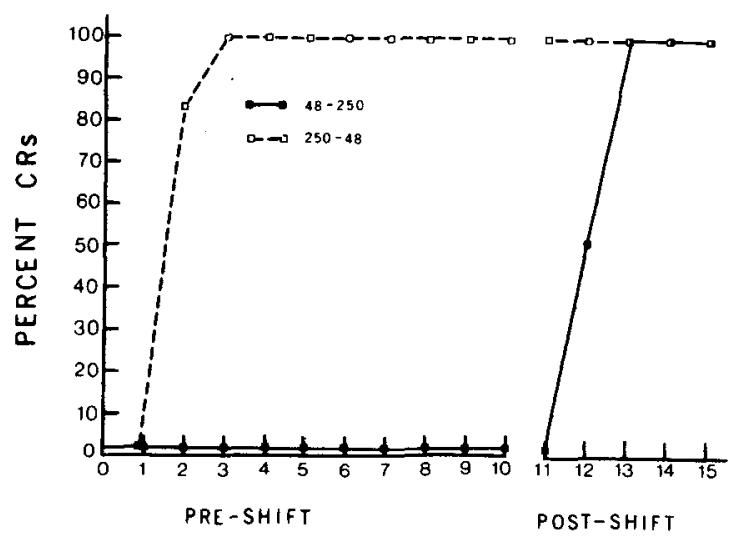

BLOCKS OF 20 TRIALS

Figure 2. Mean percent of test-trial CRs during 10 days of acquisition at 48 - or 250 -msec ISI, followed by reversal of ISI for the last 5 days. 
Again, attempting to discover some effect of the first 10 days of conditioning at $48-\mathrm{msec}$ ISI, a 2 by 5 ANOVA was performed comparing the test-trial performance of Group 250-48 on Days 1-5 with that of Group 48-250 on Days 11-15. However, as was the case with all trials, the only statistically reliable effect was trial blocks $[\mathrm{F}(4,20)=28.47, \mathrm{p}<.001]$, while there was no significant difference between the groups $(F<1)$ and no interaction $(F<1)$. Thus, the test-trial analysis supported the suggestion that neither facilitation nor interference with subsequent acquisition resulted from the first 10 days of conditioning at the short ISI.

CR-onset latency. In a further attempt to assess differences between the two groups, CR-onset latencies were measured on test trials and a 2 by 3 mixed factorial ANOVA was computed on the latencies for Group 48-250, Days 13-15 vs. Group 250-48, Days 3-5. These days were chosen for comparison because, earlier in conditioning, not enough CRs were available in both groups to permit meaningful comparison. The analysis revealed, as expected, that there were no statistically reliable differences. Again, the data suggest that the first 10 days of CS-US pairing had no measurable associative effect at the short ISI.

CR amplitude. Because CRs were evident only on test trials for Group 250-48 after the shift, it was clear that the frequency analysis did not present an adequate depiction of events. However, there was evidence of a progressive decline in test-trial CR amplitudes so that a more complete amplitude analysis seemed appropriate. Figure 3 presents this analysis. To construct the graph, the amplitude of each

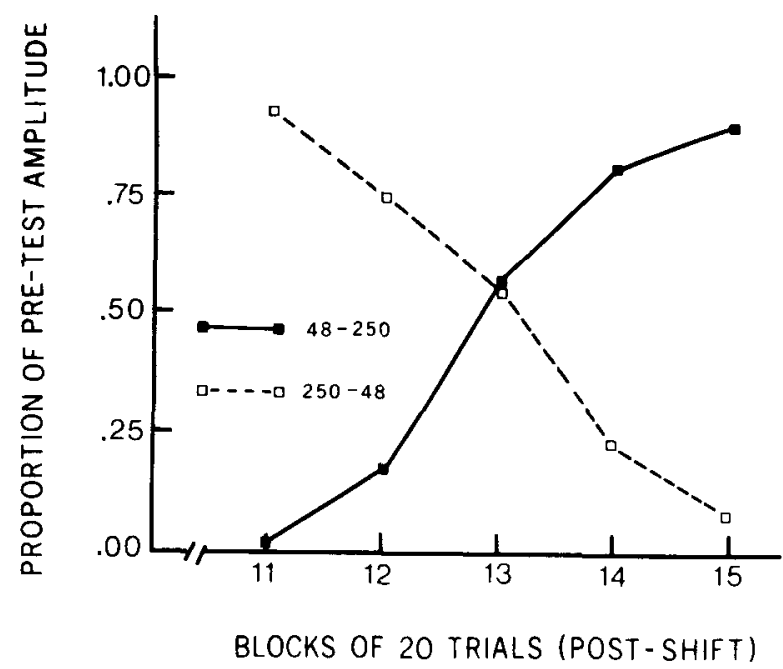

Figure 3. Amplitude proportions during the 5 postshift days. Proportions were computed by dividing each CS-alone test-trial amplitude by the amplitude of the response on the immediately preceding CS-US paired trial.
CS-alone test trial was expressed as a proportion of the response amplitude of the immediately preceding CS-US paired trial. Normally, as acquisition proceeds, this proportion increases, becoming asymptotic to 1.00. Amplitude proportions during extinction may be calculated by expressing the amplitude as a proportion of the ampltude on one or more CS-US paired trials run before the start of extinction. Normally, this proportion should decrease toward zero as extinction proceeds.

Figure 3 reveals that the animals previously conditioned at $250-\mathrm{msec}$ ISI displayed a pattern of amplitude proportions characteristic of extinction. Even though these animals continued to receive 18 daily CS-US paired trials, the test-trial CR amplitudes diminished rapidly, the amplitude proportion having dropped from .92 on Day 11 to .08 on Day 15. On the other hand, for Group 48-250, the CR amplitudes increased rapidly from zero (no CRs) on Day 11 to a mean proportion of .89 on Day 15 . A 2 by 5 mixed factorial ANOVA showed, not surprisingly, that most of the variance occurred in the Groups by Trial Blocks interaction $[F(4,20)=20.21, p<.001]$, while neither of the main effects approached statistical significance.

\section{EXPERIMENT 2}

The results of Experiment 1 suggested rather strongly that little or no conditioning occurred at an ISI of $48 \mathrm{msec}$ and that a previously acquired CR was not able to be maintained at so short an ISI. Substantial verification of this finding would be provided if a gradient of postshift transfer effects could be demonstrated, with the amount of transfer diminishing as a function of decreasing preshift ISI. Experiment 2 was designed to evaluate such a gradient. Since the study of Smith et al. (1969) had already demonstrated a modest amount of conditioning at $100-\mathrm{msec}$ ISI, and since both that study and Experiment 1 of the present study found no conditioning at 50 and $48 \mathrm{msec}$, respectively, a set of intermediate values was chosen for evaluation in Experiment 2.

\footnotetext{
Method

Subjects. The subjects were 28 rabbits obtained, housed, and fed as in Experiment 1 . Initially, seven rabbits were randomly assigned to each of four groups, but two died prior to the start of experimentation, leaving Ns of either six or seven per group.

Apparatus and Procedure. The apparatus and procedures were the same as in Experiment 1, with the exception of the ISI values chosen. The intended ISI values were $60,70,80$, or $90 \mathrm{msec}$. However, our subsequent ability to calibrate the timers revealed that the actual intervals were $57,67,76$, and $85 \mathrm{msec}$, so that the four experimental groups were so designated. Each of the four groups was run for 10 daily sessions at the assigned ISI, then shifted to an ISI of $250 \mathrm{msec}$ for the next five sessions.

For this experiment, the criteria for scoring CRs were modified slightly. A number of researchers (e.g., Salafia et at., 1974)
} 
have shown that reflexive NMRs reliably occur from 30 to $40 \mathrm{msec}$ after UR onset. Since the ISIs employed in the present experiment were so short that some CRs were undoubtedly obscured by URs, it was decided that on paired trials, during the first 10 days, a response that occurred within $20 \mathrm{msec}$ after US onset should properly be designated as a CR. The CR-scoring criteria for test trials remained the same as in Experiment 1, with any response between CS onset and $1 \mathrm{sec}$ following US offset counting as a CR.

\section{Results and Discussion}

CR frequency, all trials. Figure 4 presents acquisition curves for the four groups. During the initial 10 sessions, there was no evidence of conditioning at ISIs of 57 or $67 \mathrm{msec}$. However, after the shift, the 67-msec group showed slightly faster acquisition than the 57-msec group. On the other hand, animals conditioned at 76 and $85 \mathrm{msec}$ showed some conditioning during the preshift phase. Most of the CRs occured on test trials, although a few could be seen on paired trials as a result of the definition of CRs as responses in the ISI or up to $20 \mathrm{msec}$ after US onset. Analysis of preshift CR-onset latencies revealed that the lowest values ranged between about 90 and $100 \mathrm{msec}$. The rapid increase in CR frequency after the shift for these two groups suggests, however, that a number of longer latency CRs may have been obscured by URs during preshift sessions. Alternatively, it is possible that the emerging CRs may have been suppressed as a function of the brevity of the ISIs for these groups and then rebounded after the shift. There were too few CRs to be able to evaluate this alternative fully, but there were two subjects (one in each group) for which the test-trial CR amplitudes increased initially but then appeared to decrease slightly.

The pattern of postshift performance of the four groups clearly revealed the postulated gradient, with acquisition rate systematically related to the preshift ISI values. A 4 by 5 mixed factorial ANOVA on the

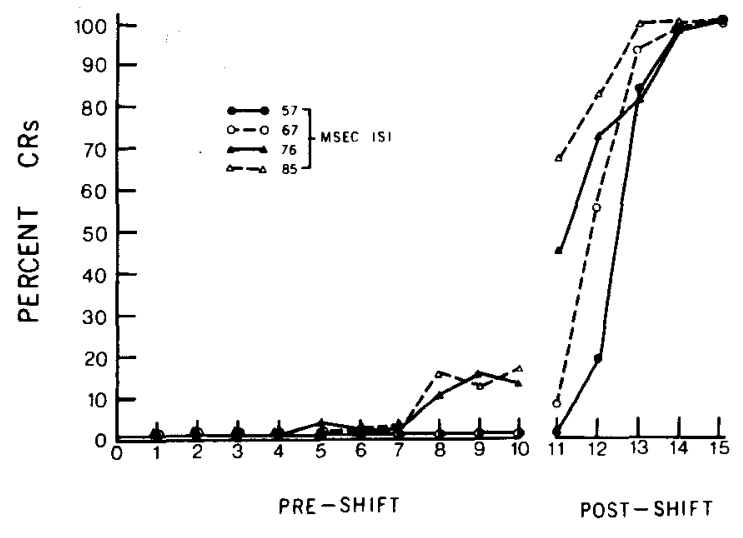

BLOCKS OF 20 TRIALS

Figure 4. Mean percent CRs during 10 days of acquisition at the indicated ISI followed by a shift for all groups to 250 -msec ISI during the last 5 days.

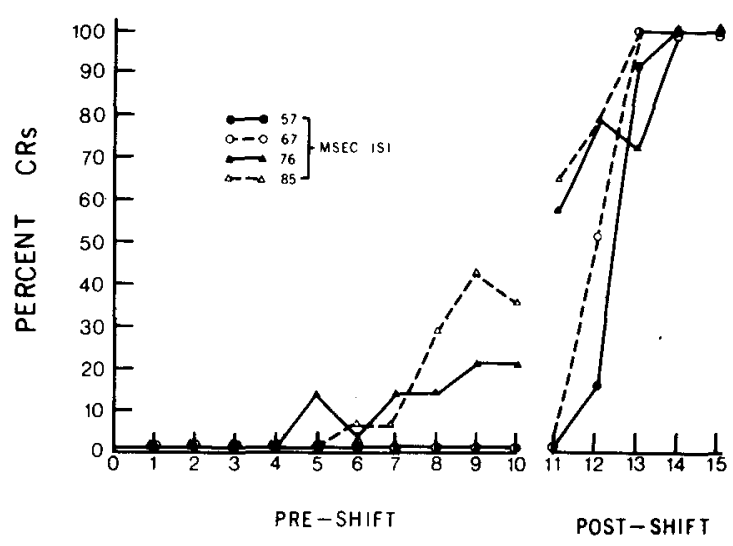

BLOCKS OF 20 TRIALS

Figure 5. Mean percent of test-trial CRs during 10 days of acquisition at the indicated ISI followed by a shift for all groups to 250-msec ISI during the last 5 days.

postshift frequency data revealed that there was a significant ISI effect $[F(3,22)=4.54, p<.025]$, but more importantly, there was a highly significant ISI by Trial Blocks interaction $[F(12,88)=4.32$, $p<$ $.001]$. The Trial Blocks effect was also significant $[\mathrm{F}(4,88)=58.32, \mathrm{p}<.001]$, as expected.

CR frequency, test trials. Figure 5, which presents test-trial acquisition curves for the four groups, displays essentially the same pattern of results, with a clear gradient of both pre- and postshift performance. The overall pattern is not quite as orderly as that seen in Figure 4, due to the fact that there were only two daily test trials. Thus, small differences in the number of CRs made on test trials have a proportionately greater effect when only test trials are considered. Nevertheless, a 4 by 5 mixed factorial ANOVA performed on the postshift data again revealed a significant effect of the preshift ISI $[F(3,22)$ $=3.14, \mathrm{p}<.05]$, Trial Blocks $[\mathrm{F}(4,88)=43.71$, $\mathrm{p}$ $<.001]$, and ISI by Trial Blocks interaction $[\mathrm{F}(12,88)$ $=4.78, \mathrm{p}<.001]$.

Postshift onset latency. Mean onset latencies of the first four CRs occurring on postshift test trials were $166,149,123$, and $115 \mathrm{msec}$ for Groups 57, 67, 76, and 85 , respectively, making the correlation between preshift ISI and postshift onset latency -.98 for the four groups. Thus, at the shorter preshift ISI (Groups 57 and 67), where little or no conditioning took place during the first 10 days, the longer postshift latencies reflect conditioning associated primarily with the 250-msec ISI. For purposes of comparison, the mean latency of the first four test-trial CRs made during the preshift phase of Experiment 1 for Group 250-48 was found to be $156 \mathrm{msec}$. On the other hand, with the longer preshift ISIs (Groups 76 and 85), some conditioning occurred late in the preshift sessions, so that the postshift CR-onset latencies seemed to reflect the pressure to respond rapidly as a function of the preshift ISI values. 


\section{EXPERIMENT 3}

Experiment 3 was essentially a replication of Experment 2 , but with a range of ISI values that would allow for a considerable amount of preshift conditioning at the higher values. We felt that the wider range of values might clarify some relationships, such as that between ISI and both CR-onset latencies and CR amplitudes. Additionally, there was the problem of the irregular ISI values employed previously because of our inability to calibrate the timers. Prior to the start of Experiment 3, we acquired a programmable timer (Heath-Schlumberger, SM-102A) which permitted precise measurement of all intervals.

\section{Method}

Subjects. The subjects were 16 rabbits housed and fed as in the previous experiments. Four rabbits were assigned randomly to each of four groups.

Apparatus and Procedure. The apparatus and procedures were as in Experiment 2, with the exception of the ISI values, which were $50,75,100$, or $125 \mathrm{msec}$ for the four groups. Again, after 10 daily sessions of 20 trials, the ISI was shifted for all groups to $250 \mathrm{msec}$.

\section{Results and Discussion}

CR frequency. The results are summarized in Figures 6 and 7, which present acquisition curves for all trials and test trials, respectively. Again, it may be seen that, at the shortest ISI $(50 \mathrm{msec})$, there was no evidence of preshift conditioning. Although no CRs were made by Group 75 during the preshift phase, this group conditioned slightly faster than Group 50 after the shift. The 100-msec ISI group showed substantial conditioning during the preshift phase, but as in the 76- and 85-msec groups of Experiment 2, there was a large jump in performance after the shift. For the 125-msec ISI group, there was asymptotic and stable conditioning during the preshift phase, with no decrement in performance resulting from the

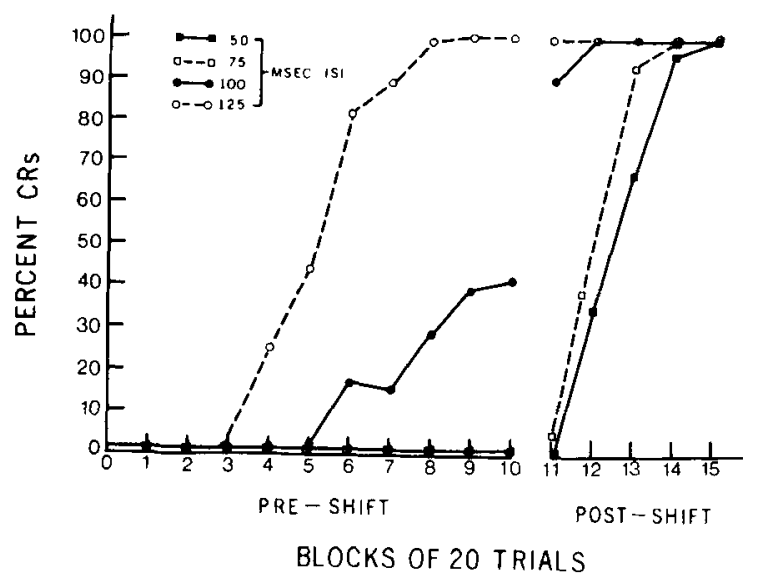

Figure 6. Mean percent CRs during 10 days of acquisition at the indicated ISI followed by a shift for all groups to $250-\mathrm{msec}$ ISI during the last 5 days.

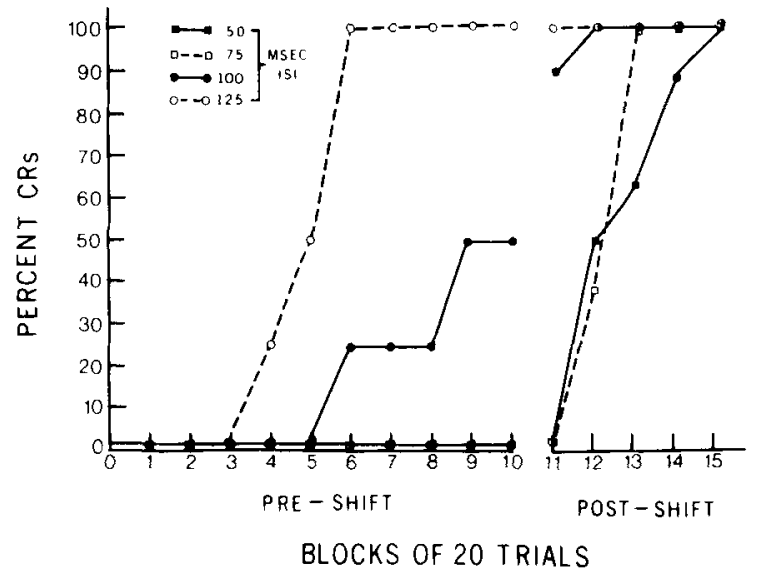

Figure 7. Mean percent of test trial CRs during 10 days of acquisition at the indicated ISI followed by a shift for all groups to 250-msec ISI during the Jast 5 days.

shift. Thus, Experiment 3 successfully replicated and extended the basic pattern of the results of Experiment 2 . The transition point between no conditioning and slight conditioning seems to be quite firmly located above $50 \mathrm{msec}$ but below $75 \mathrm{msec}$. Mixed factorial analyses of variance on both preshift and postshift CR-frequency data for all trials, as well as test trials only, revealed that all main effects and interactions were statistically reliable $(p<.001$ in each instance).

It had been suggested that the rapid post-shift increase in CR frequency for Groups 76 and 85 in Experiment 2 could have been due to suppression of conditioned responding prior to the shift, as a function of the brief ISIs. Analysis of CR amplitudes of Groups 100 and 125 in Experiment 3 failed to support this hypothesis. During the preshift phase, test trial CR amplitudes progressively increased relative to the pretest amplitudes. Thus, the initial suggestion that this rapid shift in performance was due to the presence, during the preshift phase, of a number of long-latency CRs that were obscured by URs seems most tenable.

Postshift CR-onset latency. The CR-onset latencies measured on the first four postshift test trials again revealed the inverse relationship with preshift ISI $(r=-.95)$. The mean latencies were $163,159,121$, and $108 \mathrm{msec}$, for the $50-, 75-, 100-$, and $125-\mathrm{msec}$ ISIs, respectively. With the exception of the mean latency of $159 \mathrm{msec}$ for Group 75, these latencies parallel those of Experiment 2. This one exception resulted from the slightly poorer performance of the 75 -msec group of the present experiment as compared with the 76-msec group of Experiment 2. However, this small difference is presumed to reflect an overall difference in acquisition rate across experiments, since Group 50 also conditioned slightly more slowly than the approximately comparable groups (Groups 48 and 57) from the previous experiments. Nevertheless, as before, the CR-onset latencies appear to reflect 
acquisition associated primarily with the postshift ISI for groups that failed to condition during the preshift phase (Groups 50 and 75), while they reflect acquisition associated primarily with the preshift ISI in those instances where there was substantial preshift conditioning (Groups 100 and 125).

\section{GENERAL DISCUSSION}

In three overlapping experiments, it was shown that classical NMR conditioning in the rabbit diminishes with decreasing ISI, reaching what appears to be a level of zero associative strength at ISIs of about $57 \mathrm{msec}$ or less. Shifting to a relatively optimal ISI of $250 \mathrm{msec}$ after 10 days of CS-US pairing revealed no evidence of either facilitation or inhibition for groups initially conditioned at ISIs of 48,50 , or $57 \mathrm{msec}$. At longer ISIs of $67,75,76,85,100$, and $125 \mathrm{msec}$, there was a progressive increase in acquisition rate with increasing ISI, as reflected in both preand postshift performance.

Analysis of $C R$-onset latencies provided support for these CR-frequency results in that the latencies were highly correlated with preshift ISI for the longer ISI values and with the postshift ISI for the shorter values where there was little or no preshift conditioning. Further evidence was provided by analysis of test-trial CR amplitudes which displayed the usual progressive increase for all groups in Experiments 2 and 3. The one group which deviated from this rule was Group 250-48 in Experiment 1. After the shift to a 48-msec ISI, CR amplitudes displayed the progressive decrease characteristic of extinction (Figure 3 ).

Part of the impetus for the present research had been the identification of a suitable control condition with forward pairing in which there would be absolutely no conditioned responding. Such a control condition would be of considerable value in the study of electrophysiological aspects of conditioning (e.g. Berger, Alger, \& Thompson, 1976; Berger \& Thompson, 1977; Thompson, 1976). Recently, Hoehler and Thompson (Note 1) reported that hippocampal multiple unit activity is, indeed, strongly influenced by ISI. These investigators reported that, at 50-msec ISI, hippocampal unit activity was at about the same level as that of an unpaired control group, while activity recorded at ISIs of 150 and $250 \mathrm{msec}$ showed the phase-lead unit response reported in the earlier studies of Berger et al. and Berger and Thompson. Assuming that this hippocampal unit activity recorded during NMR conditioning is actually a neuronal representation of some aspect of the associative process, the results of Hoehler and Thompson support the basic conclusion that little or no associative strength develops with very brief ISIs.

It could be argued that while there was no apparent conditioning during the preshift phase with short ISIs, some associative strength had developed, which was subsequently obscured by a shift-induced decre- ment in performance such as has been observed in some recent experiments (e.g., Coleman \& Gormezano, 1971). This explanation seems implausible, however, in light of the large postshift increments in performance displayed by the groups conditioned at the longer preshift ISIs (Experiment 2, Groups 76 and 85; Experiment 3, Group 100), as well as by the absence of any shift-induced decrement in the 125-msec group of Experiment 3, which had reached $100 \%$ CRs during the preshift phase. Furthermore, Salafia, Martino, Cloutman, and Romano (1979) have found that when the US is circumorbital shock, as in the present study, there is little or no decrement when shifting from a short to a long ISI.

It was somewhat surprising, however, to note that, at the shorter ISIs, 10 days of conditioning produced absolutely no discernible effects. One might reasonably expect that, even if no excitatory conditioning took place, there might at least be evidence of the development of some inhibitory tendency such as latent inhibition (LI). However, Lubow, Alek, and Arzy (1975) and Lubow, Schnur, and Rifkin (1976) have provided a mechanism by which such effects, if potentially present, might have been eliminated. Basically, their conditioned attention theory argues that any environmental change (such as the US in the present case) following the to-be-CS during preexposure should attenuate LI by maintaining attention to the CS. Indeed, Lubow et al. argue that this is one of the functions of the US in the usual conditioning situation. It is possible that such a mechanism was operative in the present experiments, although further research with appropriate LI control groups would be necessary to evaluate this possibility.

Although simultaneous and backward conditioning were not evaluated in the present study, the results nevertheless cast serious doubt on the likelihood of Pavlovian conditioning of a specific response such as the NMR employing the simultaneous or backward paradigm. Thus, if foreward pairing at 48-, 50-, and 57 -msec ISI produced neither preshift acquisition nor postshift savings, there seems to be no reason to expect acquisition with shorter ISI values. It should be mentioned that the only experiment in which substantial conditioning was obtained at an ISI as short as $50 \mathrm{msec}$ involved inferior colliculus stimulation as the CS (Patterson, 1970). Presumably, this conditioning was achieved because the external sensory mechanisms were bypassed and the neural distance between the point of application of CS and association centers was decreased.

Furthermore, two recent experiments have failed to find any evidence of excitatory backward conditioning in the rabbit. Plotkin and Oakley (1975), who carefully controlled for latent inhibition effects, safety-signal effects, and the like, found no excitatory backward conditioning but, rather, retardation of subsequent forward conditioning in two groups 
which previously had received 150 US-CS pairings. In another study, Stern and Frey (1978) used secondorder conditioning as a potentially more sensitive index of backward conditioning effects and found no evidence for the phenomenon in rabbits.

Finally, why does the lower limit of ISI for NMR conditioning employing an externally applied CS and US lie between about 57 and $67 \mathrm{msec}$ ? It might be argued that very short ISIs do not permit sufficient time for a predictive relationship or contingency (Rescorla, 1967) to be formed between CS and US. Although, from the behavioral point of view, this explanation may be quite valid, there may be a more direct physiological basis. There appear to be two major response characteristics which could be related to the value of the lower limit. First, the time required for the reflexive elicitation of the NMR by circumorbital shock is about 30 to $\mathbf{4 0} \mathrm{msec}$ (Salafia et al., 1974). Second, the minimum CR-onset latencies observed in the present study were on the order of 90 to $100 \mathrm{msec}$. The range of differences between these values, 50 to $70 \mathrm{msec}(90-40=50 ; 100-30$ $=70$ ), may define the minimum time required for the neural processes underlying the association between CS and US. We believe that it is not merely coincidental that the difference between minimum UR and CR latencies is of the same order of magnitude as the transition range between no acquisition and acquisition.

\section{REFERENCE NOTE}

1. Hoehler, F. K., \& Thompson, R. F. Multiple unit activity in the hippocampus as a function of CS.US interval during classical conditioning of the rabbit's nictitating membrane response. Paper presented at the meeting of the Psychonomic Society, Washington, D.C., November 1977.

\section{REFERENCES}

Ayres, J. B., Mahoney, W. J., Proulx, D. T., \& Benedict, J. O. Backward conditioning as an extinction procedure. Learning and Motivation, 1976, 7, 368-381.

Barker, L. M., Suarez, E. M., \& Gray, D. Backward conditioning of taste aversions in rats using cyclophosphamide as the US. Physiological Psychology, 1974, 2, 117-119.

Berger, T. W., Alger, B., \& Thompson, R. F. Neuronal substrate of classical conditioning in the hippocampus. Science, 1976, 192, 483-485.

Berger, T. W., \& Thompson, R. F. Limbic system interrelations: Functional division among hippocampal-septal connections. Science, 1977, 197, 587-589.

Coleman, S. R., \& Gormezano, I. Classical conditioning of the rabbit's (Oryctolagus cuniculus) nictitating membrane response under symmetrical CS-US interval shifts. Journal of Comparative and Physiological Psychology, 1971, 77, 447-455.

Heth, C. D., \& Rescorla, R. A. Simultaneous and backward fear conditioning in the rat. Journal of Comparative and Physiological Psychology, 1973, 82, 434-443.

Keith-Lucas, T., \& Guttman, N. Robust-single-trial delayed backward conditioning. Journal of Comparative and Physiological Psychology, 1975, 88, 468-476.

Lubow, R. E., Alek, M., \& Arzy, J. Behavioral decrement following stimulus preexposure: Effects of number of preexposures, presence of a second stimulus, and interstimulus interval in children and adults. Journal of Experimental Psychology: Animal Behavior Processes, 1975, 104, 178-188.

Lubow, R. E., Schnur, P., \& Rifkin, B. Latent inhibition and conditioned attention theory. Journal of Experimental Psychology: Animal Behavior Processes, 1976, 2, 163-174.

Mahoney, W. J., \& Ayres, J. B. One-trial simultaneous and backward fear conditioning as reflected in conditioned suppression of licking in rats. Animal Learning \& Behavior, 1976, 4, 357-362.

Patterson, M. M. Classical conditioning of the rabbit's (Oryctolagus cuniculus) nictitating membrane response with fluctuating ISI and intracranial-CS. Journal of Comparative and Physiological Psychology, 1970, 72, 193-202.

Plotkin, H. C., \& OAkley, D. A. Backward conditioning in the rabbit (Oryctolagus cuniculus). Journal of Comparative and Physiological Psychology, 1975, 88, 586-590.

Rescori,A, R. A. Pavlovian conditioning and its proper control procedures. Psychological Review, 1967, 74, 71-80.

Sal.afia, W. R., Daston, A. P., Bartosiak, R. S., Hurley, J., \& Martino, L. J. Classical nictitating membrane conditioning in the rabbit (Oryctolagus cuniculus) as a function of unconditioned stimulus locus. Journal of Comparative and Physiological Psychology, 1974, 86, 628-636.

Salafia, W. R., Martino, L. J., Cloutman, K., \& Romano, A. G. Unconditioned-stimulus locus and interstimulus-interval shift in rabbit (Oryctolagus cuniculus) nictitating membrane conditioning. Pavlovian Journal of Biological Science, 1979, 14, 64-71.

Singel, S., \& Domdan, M. The inhibitory effect of backward conditioning as a function of the number of backward pairings. Bulletin of the Psychonomic Society, 1974, 4, 122-124.

Smith, M. C., Coleman, S. R., \& Gormezano, I. Classical conditioning of the rabbit's nictitating membrane response at backward, simultaneous, and forward CS-US intervals. Journal of Comparative and Physiological Psychology, 1969, 69, 226-231.

Stern, S. D., \& FreY, P. W. Backward conditioning of the rabbit eyelid response: A test using second-order conditioning. Bulletin of the Psychonomic Society, 1978, 11, 231-234.

Thompson, R. F. The search for the engram. American Psychologist, 1976, 31, 209-227.

WAgner, A. R., \& TERRY, W. S. Backward conditioning to a CS following an expected vs. a surprising UCS. Animal Learning \& Behavior, 1975, 3, 370-374.

(Received for publication January 16, 1979; revision accepted September $11,1979$. 